\title{
Does the risk of hospitalisation for ischaemic heart disease rise already before widowhood?
}

\section{Einiö, Elina}

2017

Einiö , E , Moustgaard , H , Martikainen , P \& Leinonen , T 2017 , ' Does the risk of hospitalisation for ischaemic heart disease rise already before widowhood? ' , Journal of Epidemiology \& Community Health , vol. 71 , no. 6 , pp. 599-605 . https://doi.org/10.1136/jech-2016-207987

http://hdl.handle.net/10138/236226

https://doi.org/10.1136/jech-2016-207987

acceptedVersion

Downloaded from Helda, University of Helsinki institutional repository.

This is an electronic reprint of the original article.

This reprint may differ from the original in pagination and typographic detail.

Please cite the original version. 


\title{
Does the risk of hospitalization for ischemic heart disease rise already before widowhood?
}

\author{
Elina Einiö, Heta Moustgaard, Pekka Martikainen, Taina Leinonen \\ Correspondence to Elina Einiö, \\ Population Research Unit, \\ Department of Social Research, \\ University of Helsinki, \\ PO Box 18, FIN-00014 Helsinki, Finland, \\ elina.einio@helsinki.fi
}

\begin{abstract}
Background. The death of a spouse has been shown to increase mortality from various causes, including ischemic heart disease. It is unclear, however, whether cardiac problems are already on the rise before widowhood. Methods. Using longitudinal register data of Finnish widows-to-be $(\mathrm{N}=19,185)$, we assessed the risk of hospitalization for ischemic heart disease 18 months before and after widowhood. Hospital admissions were derived from national hospital discharge registers between 1996-2002. Analyses utilized population-averaged and fixed-effects logistic models, the latter of which controlled for unobserved time-invariant characteristics, such as genetic susceptibility, personality, and behavioral and medical history. Results. For men, fixed-effects model revealed that hospitalization for ischemic heart disease increased two-fold already 0-3 months prior to the death of a spouse (odds ratio $(\mathrm{OR})=2.09,95 \%$ confidence interval $(\mathrm{Cl}): 1.22$, $3.60)$, relative to the period of 15-18 months before widowhood. It stayed at a heightened level up to 6 months following bereavement $(\mathrm{OR}=2.15,95 \% \mathrm{Cl}: 1.07,4.30)$. Among women, the fixedeffects analysis detected no statistically significant increase in hospitalization for ischemic heart disease before widowhood. Conclusions. These findings indicate that men are already vulnerable to cardiac problems before the death of a wife. Medical interventions and health counseling could be targeted to the husbands of terminally ill patients, in order to improve their cardiovascular health over the transition to widowhood.
\end{abstract}




\section{INTRODUCTION}

Several studies show that the risk of death from all-causes,[1-8] unnatural causes, [9-11] certain cancers, and ischemic heart diseases[10,11] rise after the death of a spouse. Most studies indicate that the risk of death is highest during the first weeks[6,9] or months[1,2,4,7,8,12,13] following the spouse's death, while one study from the United States indicates the highest risk as late as 7-12 months following bereavement.[5] Despite contextual and methodological differences between the studies, the effect of a broken heart after having lost a spouse has become a widely accepted paradigm in medical and social sciences.[11,14,15] One recent study from the United States even showed that the likelihood of an acute myocardial infarction (MI) was elevated during the first month following the death of a significant person.[16] It has been suggested that bereavement increases susceptibility to physical illnesses,[14] which can be observed in an older individual's immune system shortly after the loss.[17,18] Most studies, however, compare bereaved individuals with their non-bereaved counterparts,[14] as if the death of a spouse was an external unexpected shock for the surviving spouse. Yet, the death of a fragile or ill spouse may be expected, and its anticipation may already trigger heart problems.

To our knowledge, no study has analyzed cardiovascular health shortly before widowhood, which could provide an opportunity to enhance our understanding of the complex process of losing a spouse. In a study of Americans over 50 years old, Vable et al.[19] showed that widows-to-be had worse depressive symptoms, mobility and cognitive problems than those continuously married. Similarly, Williams et al.[20] suggested that widows-to-be differed from those continuously married by demonstrating their higher levels of anxiety and depressive symptoms, as well as poorer self-reported health. Also the few studies utilizing repeated measures of health before and after widowhood indicate that depressive symptoms are already on the rise before the death of a spouse.[21,22] Because depression and emotional distress in general are suggested to predispose individuals to ischemic heart disease, $[23,24]$ it is likely that heart problems also aggravate or occur prior to widowhood.

This study used unique register-based longitudinal data on Finnish widows to analyze the risk of hospitalization for ischemic heart disease 18 months before and 18 months after the 
death of a spouse, at three-month intervals. We used both 1) a standard population-averaged model that controls for observed characteristics, such as education, gender, age and calendar year, and 2) a fixed-effects logistic model that also controls for unobserved time-invariant characteristics of the individuals, such as genetic makeup, personality, and behavioral and medical history. Controlling for unobserved characteristics is important because many of them are likely to be correlated with both the timing of widowhood and health, and hence bias the population-averaged estimates.

\section{METHODS}

\section{Data}

The data were based on a $40 \%$ random sample of older persons aged 65 and older who resided in Finland on December 31, 1997. The sample from Statistics Finland was linked with death records and hospital discharge records from the National Research and Development Centre for Welfare and Health (permission numbers: TK-53-576-04, TK-53-499-05). The linkage was carried out using 11-digit personal identification codes.

Of the 301,265 persons aged 65 and over captured in the random sample, $45.2 \%$ lived with a spouse on December 31, 1997. To focus our analyses on those who experienced spousal bereavement, we excluded those whose spouse survived from January 1, 1998 to December 31, 2002. We also excluded those few persons who died on the same day as their spouse. Thus, the analytical sample (standard population-averaged model) consisted of 19,185 persons whose spouse died within the five-year follow-up period. The subsample for the second analysis (individual fixed-effects models) included those 1,611 widows who had at least one hospital admission for ischemic heart disease 18 months before or after the death of their spouse. The restriction of the analysis to this subsample was due to the constraints of fixed-effects modeling, which require within-individual variation in the outcome. The characteristics of the samples are shown in Table 1. 
Table 1. Sample characteristics of persons who experienced the death of a spouse between 19982002, Finland

\begin{tabular}{llll}
\hline & Total & Men & Women \\
\hline Main sample & $\mathrm{n}=19,185$ & $\mathrm{n}=5,773(30.1 \%)$ & $\mathrm{n}=13,412(69.1 \%)$ \\
$\quad$ Year of birth, mean (SD) & $1923.2(5.8)$ & $1921.7(6.4)$ & $1923.8(5.5)$ \\
Age at entry, mean (SD) & $74.8(5.9)$ & $76.2(6.4)$ & $74.2(5.6)$ \\
$\quad$ Age at widowhood, mean (SD) & $76.3(5.9)$ & $77.7(6.4)$ & $75.7(5.6)$ \\
$\quad$ Education level & & & \\
$\quad$ Tertiary & $8.5 \%$ & $12.1 \%$ & $6.9 \%$ \\
$\quad$ Intermediate & $12.8 \%$ & $11.9 \%$ & $13.2 \%$ \\
$\quad$ Basic or less & $78.7 \%$ & $76.0 \%$ & $79.8 \%$ \\
Hospitalized for IHD (a) & $8.4 \%$ & $11.3 \%$ & $7.2 \%$ \\
& & & \\
Subsample & $\mathrm{n}=1,611$ & $\mathrm{n}=650(40.3 \%)$ & $\mathrm{n}=961(59.7 \%)$ \\
$\quad$ Year of birth, mean (SD) & $1920.9(6.1)$ & $1919.9(6.3)$ & $1921.6(5.8)$ \\
Age at entry, mean (SD) & $77.0(6.1)$ & $78.0(6.4)$ & $76.3(5.8)$ \\
Age at widowhood, mean (SD) & $78.4(6.1)$ & $79.5(6.4)$ & $77.7(5.7)$ \\
Education level & & & \\
$\quad$ Tertiary & $6.3 \%$ & $8.2 \%$ & $5.0 \%$ \\
$\quad$ Intermediate & $11.0 \%$ & $11.8 \%$ & $11.1 \%$ \\
$\quad$ Basic or less & $82.7 \%$ & $81.1 \%$ & $83.9 \%$ \\
\hline
\end{tabular}

Abbreviations: SD, standard deviation; IHD, ischemic heart disease

(a) Proportion hospitalized for IHD 18 months before or after widowhood

\section{Ischemic heart disease}

The data on the principal cause of hospitalization was based on the Tenth Revision of the International Statistical Classification of Diseases and Related Health Problems (ICD-10) .[25] Hospitalization for ischemic heart disease included admissions due to the following diagnoses: angina pectoris (ICD-10 code I20), myocardial infarctions (I21-I22), complications following myocardial infarctions (I23), other acute ischemic heart diseases (I24), and chronic ischemic heart diseases (125). The diagnoses and admission dates were identified from the national hospital discharge records between 1996-2002. If a study person died from ischemic heart disease without being hospitalized, he or she was not considered hospitalized, and thus was not included as a case in our outcome measure. This decision was based on the principle of clarity and symmetry of the study design, since, by definition, widows-to-be cannot die before their spouses. 


\section{Statistical analysis}

Individuals were followed for 18 months before and 18 months after the death of their spouse. The proximity to widowhood was divided into six three-month (91-day) intervals around the date of widowhood (altogether 12 intervals). The outcome was categorized as 1 if a study person had at least one hospital admission for ischemic heart disease during a three-month interval and 0 otherwise. If a study person died during an interval, censoring occurred at the beginning of the next interval.

We first utilized a standard population-averaged logistic model to predict the adjusted three-month prevalence of hospitalization for ischemic heart disease before and after widowhood. These standard models use both between- and within-individual variation in the exposure and outcome to estimate the effect of the proximity to widowhood. Level of education and gender were added to the model as time-invariant covariates, and calendar year and age as time-varying covariates. The results are presented as the adjusted prevalence of hospitalization for ischemic heart disease within each three-month interval before and after widowhood by gender (Figure 1). The unadjusted prevalences were not of notable interest to us, and they are in the appendix 1.

Secondly, we used individual-level fixed-effects logistic models to analyze hospitalization for ischemic heart disease before and after the death of a spouse. The fixed-effects approach controlled for all unobserved time-invariant characteristics of individuals, such as genetic makeup, personality, and behavioral and medical history, and allowed for controlling of observed time-varying covariates, such as age and calendar year. Despite several advantages, fixed-effects models do not control for unobserved time-varying characteristics of the individuals (e.g., changes in health behavior).[26,27] Fixed-effects models were fitted separately for men and women, and the results are presented as odds ratios $(\mathrm{OR})$ with their $95 \%$ confidence intervals $(\mathrm{Cl})$. The first three-month interval, from 15-18 months before widowhood, was chosen as the reference category (Figure 2 and 3).

The Hausman test was used to determine whether a simpler random-effects model could have been used instead of a fixed-effects model. The test showed that an individual-level 
fixed-effects model was a better choice to analyze hospitalizations for ischemic heart disease (men: $p<0.0001$; women: $p=0.0107)$.

\section{Observed control variables}

We used age, calendar year, gender and level of education as observed control variables. Age and calendar year were measured at each three-month interval. Age was calculated from the date of birth and expressed in completed years. Gender and education, which were measured on December 31, 1997, were added to the models as time-invariant categorical variables. The educational categories were based on the highest educational qualification or degree completed. The three categories were: tertiary education, intermediate education, and basic education or less.

\section{RESULTS}

\section{Population-averaged model}

Among men, the prevalence of hospitalization for ischemic heart disease showed a marked increase a few months before the death of a wife, independent of observed confounders such as age, calendar year, and education (Figure 1). The three-month prevalence was between $1.0-1.1 \%$ from $3-18$ months before widowhood, increased to $1.9 \%$ from $0-3$ months prior to widowhood, and stayed above $1.5 \%$ for the 12 months following the death of a wife.

Among women, the adjusted three-month prevalence of hospitalization for ischemic heart disease was between $0.6-0.8 \%$ from 9-18 months before the death of a spouse and rose gradually to $1.1 \%$ from $0-3$ months before widowhood. This increase observed among women shortly before widowhood was less pronounced than that among men. Additionally, the prevalence for women stayed above $1.0 \%$ for at least the 18 month period after widowhood.

$<$ Figure 1> 


\section{Fixed-effects models}

For men, the risk of hospitalization due to ischemic heart disease showed a clear increase shortly before widowhood, independent of unobserved time-invariant characteristics, as well as the time-varying measures of age and calendar year (Figure 2). The odds of being hospitalized 0-3 months prior to widowhood was two-fold higher compared to that observed earlier, 15-18 months before the death of a wife $(\mathrm{OR}=2.09,95 \% \mathrm{Cl}: 1.22,3.60)$. The odds of hospitalization for ischemic heart disease remained at a heightened level for 6 months following the death of a wife $(\mathrm{OR}=2.15,95 \% \mathrm{Cl}: 1.07,4.30)$, after which it was no longer significantly higher, compared to the reference period of 15-18 months prior to widowhood (6-9 months after widowhood: OR=2.14, 95\% Cl: 0.99, 4.63, 10-12 months after widowhood: OR=2.30, 95\% Cl: 0.98, 5.39).

Among women, fixed-effects model revealed that hospitalization for ischemic heart disease was not significantly different with proximity to widowhood (Figure 3). However, the odds of hospitalization seemed somewhat elevated 0-3 months before widowhood $(\mathrm{OR}=1.37,95 \% \mathrm{Cl}$ : $0.87,2.15)$ and $0-3$ months after widowhood (OR=1.45, 95\% $\mathrm{Cl}: 0.87,2.41)$, compared to that observed 15-18 months prior to widowhood.

$<$ Figure 2>

$<$ Figure $3>$

\section{DISCUSSION}

This study was the first to include the period before a spouse's death in the assessment of the relationship between ischemic heart disease and the proximity to widowhood. Using unique longitudinal data of Finnish widows and widowers, our analysis showed that, for men, the risk of hospitalization due to ischemic heart disease increased markedly 0-3 months prior to the death of a wife, and remained at a heightened level for 6 months following the loss. This pattern was similar in both the population-averaged and fixed-effects model for men. On the contrary, among women, the prevalence of hospitalization for ischemic heart disease appeared to increase a 
few months prior to widowhood in the population-averaged model, but this result could not be verified with the fixed-effects approach which accounted for unobserved time-invariant characteristics, such as genetic makeup, personality, and medical and behavioral history. Hence, this study demonstrated a clear relationship between the proximity to widowhood and hospitalization for ischemic heart disease among men only (Figure 2 vs. Figure 3).

Our findings for men are consistent with results from a previous study in the United States showing an increased risk of heart problems after the death of a significant person.[16] In their study of surviving Ml patients who were able to complete a structured interview, Mostofsky et al.[16] indicated that the risk of an acute $\mathrm{Ml}$ was elevated within 24 hours of the death of a significant person, declining steadily on each subsequent day, but remained elevated for at least one month following the loss. The result of our study showed that men's risk of hospitalization for ischemic heart disease, which also included acute Mls, remained elevated up to six months following bereavement, compared to that observed 15-18 months prior to widowhood. However, in addition to Mls, our study also included chronic ischemic heart disease, the mortality of which has been shown to be elevated for at least six months following the death of a spouse, compared to individuals with a spouse who is still alive.[10]

As the first study looking at the period before widowhood, our results indicate that men's risk of hospitalization for ischemic heart disease began rising even prior to widowhood. This result cannot be compared with that of Mostofsky et al.[16] or those of mortality studies[10,11] because these lack repeated measures of health outcomes before bereavement. However, our findings for men are somewhat consistent with the results of an earlier Dutch study on health care expenditures 42 months before and after widowhood suggesting that the average expenditure level rises a few months before widowhood among individuals over 80 years old, and remains at a heightened level after widowhood.[28] Rolden et al.[28] suggested that the expenditure levels predominantly rose because of an increased need for formal care after the death of an informal caregiver, rather than an increased need for medical treatment related to the health impact of bereavement. This argument was justified by the fact that the increase in expenditure levels after widowhood was especially high in the long-term care sector. However, they did suggest that the 
increase in expenditure levels observed seven months before widowhood, among the oldest widows-to-be, could be related to the consequences of emotional stress and a higher burden of informal care. Additionally, in spite of a longitudinal study design, the Dutch study had no information on the diagnoses that were associated with the increase in expenditure levels over the transition to widowhood.

In our study, there are several possible explanations for the elevated risk of hospitalization due to ischemic heart disease observed in men 0-3 months before the death of a wife. First, psychosocial mechanisms that are suggested to operate after the death of a spouse may well be in place before the actual loss. The surviving husband may be aware of the approaching death of his wife and experience an increase in psychological stress, life dissatisfaction, and depressive symptoms,[21,22] which can increase susceptibility to physical illnesses.[15] Additionally, the fear of losing a spouse may cause insomnia, which has been shown to increase the risk of an acute MI.[29] Furthermore, a distressed husband may experience high blood pressure or develop harmful coping mechanisms, such as an increase in smoking and alcohol intake, which can affect his cardiovascular health.[30-32]

Secondly, it is possible that a spouse's approaching death intensifies informal caregiving burdens,[28] which can cause health problems for the caregiver. Caregiving has previously been suggested to increase the risk of ischemic heart disease.[33] However, a recent study from England indicated that caregiving was only associated with ischemic heart disease among caregivers who were already in poor health at baseline.[34] In our sample, the surviving husbands were, on average, over 75 years old at the study entry; thus, the caregiving burden could be of importance in explaining the results for the widowers.

Finally, our results may also be consistent with a scenario in which the heart problems of a husband contribute to the death of a wife. The hospitalization of a husband for a nonfatal heart disease may leave a fragile wife without a caregiver, may cause depression and anxiety, and, in the most severe case, precipitate the process leading to her death. Accordingly, Christakis and Allison[35] showed that a spouse's hospitalization for ischemic heart disease was associated with an increased risk of death among women, but not men, in the United States. 
Furthermore, in a recent Danish study, Fosbol et al.[36] showed that hospitalization of a spouse for an acute $\mathrm{Ml}$ increased the use of antidepressants and benzodiazepine medication in the nonhospitalized spouse after the event, even among those whose spouse survived. A spouse's hospitalization for other nonfatal causes had no such effect. Fosbol et al. argued that a heart attack has psychological consequences for a spouse, because he or she has to live through the serious event alongside the patient.[36] These psychological consequences may be devastating for an already ill or fragile person, possibly accelerating the natural progression of a disease, leading to an earlier death.

The main strength of our study was the identification of the date of widowhood and of the hospitalizations for ischemic heart disease before the death of a spouse. Diagnoses based on hospital registers are less vulnerable to self-report bias than surveys and the attrition rate is minimal. Of course, minor symptoms of ischemic heart disease, which did not lead to hospital use were not captured. The fixed-effects models used in the study reduced the selection bias related to unobserved differences between the individuals, since each individual served as his or her own control. However, unobserved time-varying characteristics of an individual, such as behavioral changes that are independent of widowhood, could still confound the results. Unfortunately, our register-based data did not contain any information on an individual's or a couple's health behavior. It is plausible, however, that most short-term behavioral changes occurring during the transition to widowhood are related to the process of widowhood. Therefore, more research is needed to assess changes in stress, for example biomarkers such as blood pressure, and various health behaviors among the surviving spouses prior to the death of a spouse.

\section{Conclusions}

In summary, we found that men's risk of hospitalization for ischemic heart disease increased 0-3 months before the death of a wife, and remained at a heightened level for 6 months following widowhood. This result was independent of the influences of individuals' unobserved time-invariant characteristics, such as genetic susceptibility, personality, and behavioral and medical history, and of observed time-varying characteristics, such as age and calendar year. 
These results suggest that men are already physically vulnerable to bereavement-related cardiac problems prior to the actual loss of a wife. Medical interventions and health counseling could be targeted to the husbands of terminally ill patients, in order to improve their cardiovascular health over the transition to widowhood.

\section{What is already known on this subject?}

- Mortality from ischemic heart disease is known to be elevated after widowhood

- It is unclear whether cardiac problems are already on the rise before widowhood

\section{What this study adds?}

- This is the first study to assess the risk of hospitalization for ischemic heart disease shortly before widowhood.

- This study uses fixed-effects models to control for the confounding influences of unobserved time-invariant characteristics, such as genetic susceptibility, personality, and behavioral and medical history.

- The findings indicate that men are already vulnerable to cardiac problems a few months before the actual loss of a wife. 
Figure 1. Hospitalization for ischemic heart disease 18 months before and after the death of a spouse by gender, adjusted (a) three-month prevalence (\%), Finnish widows, N=19,185

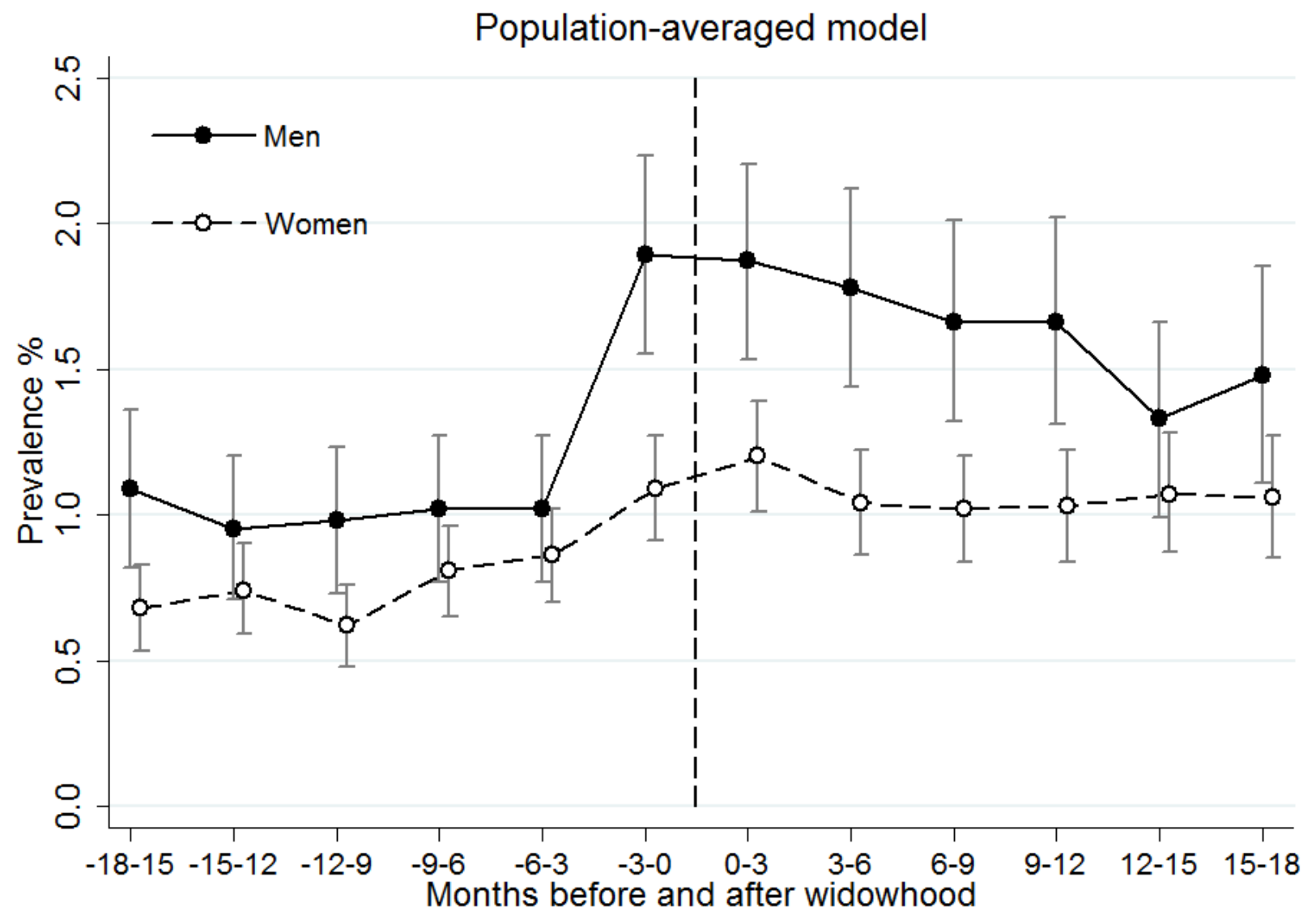

Note: (a) The population-averaged model controlled for age and calendar year (time-varying), gender and education (time-invariant), proximity to widowhood, and the interaction between proximity to widowhood and gender. 
Figure 2. Odds ratios for men of hospitalization due to ischemic heart disease 18 months before and after the death of a wife (ref. = 15-18 months before), fixed-effects model (a), widowed men, $\mathrm{N}=650$

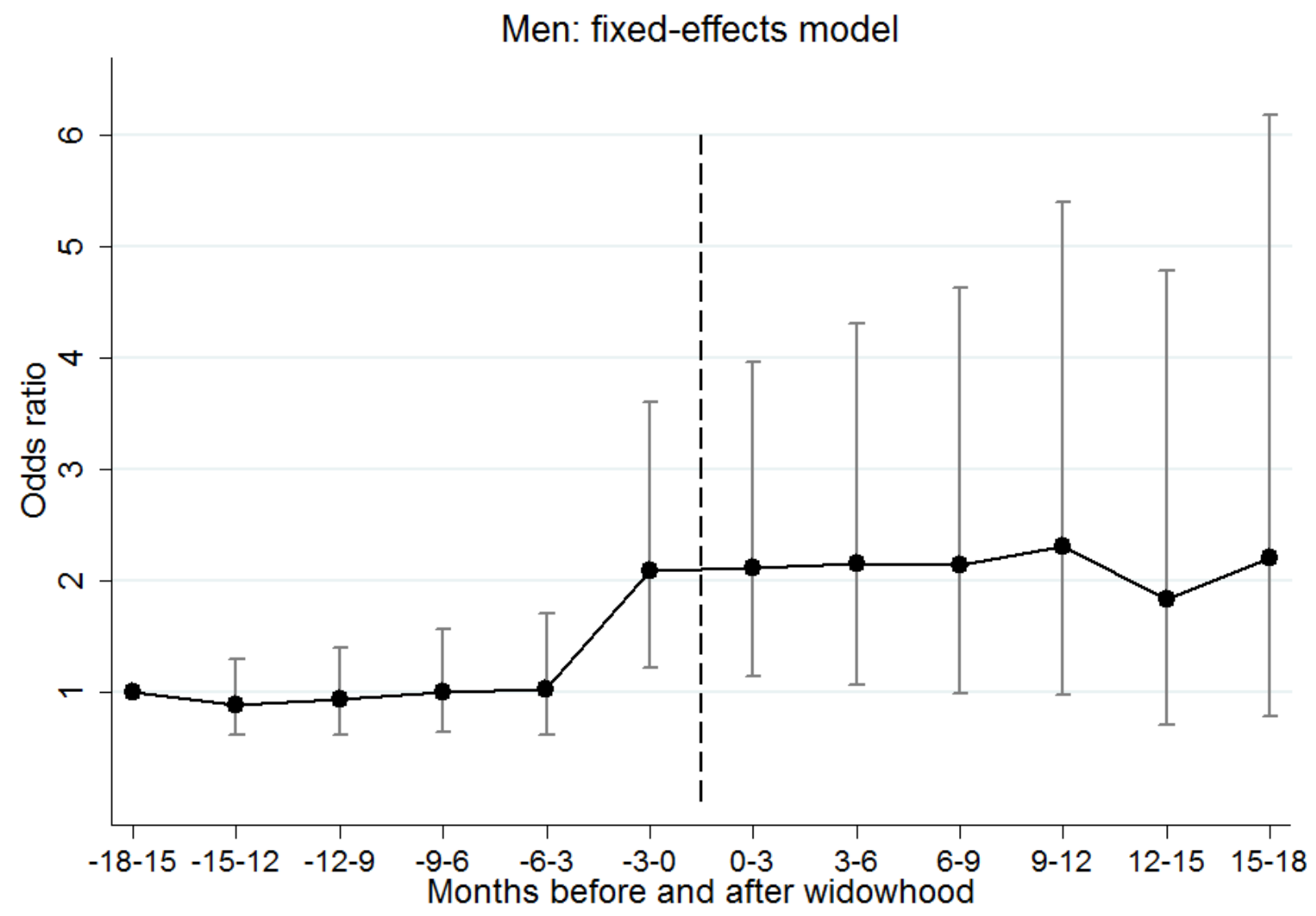

Note: (a) The fixed-effects logistic model controlled for observed time-varying age and calendar year and all unobserved time-invariant confounders. 
Figure 3. Odds ratios for women of hospitalization for ischemic heart disease 18 months before and after the death of a husband (ref. = 15-18 months before), fixed-effects model (a), widowed women, $\mathrm{N}=961$

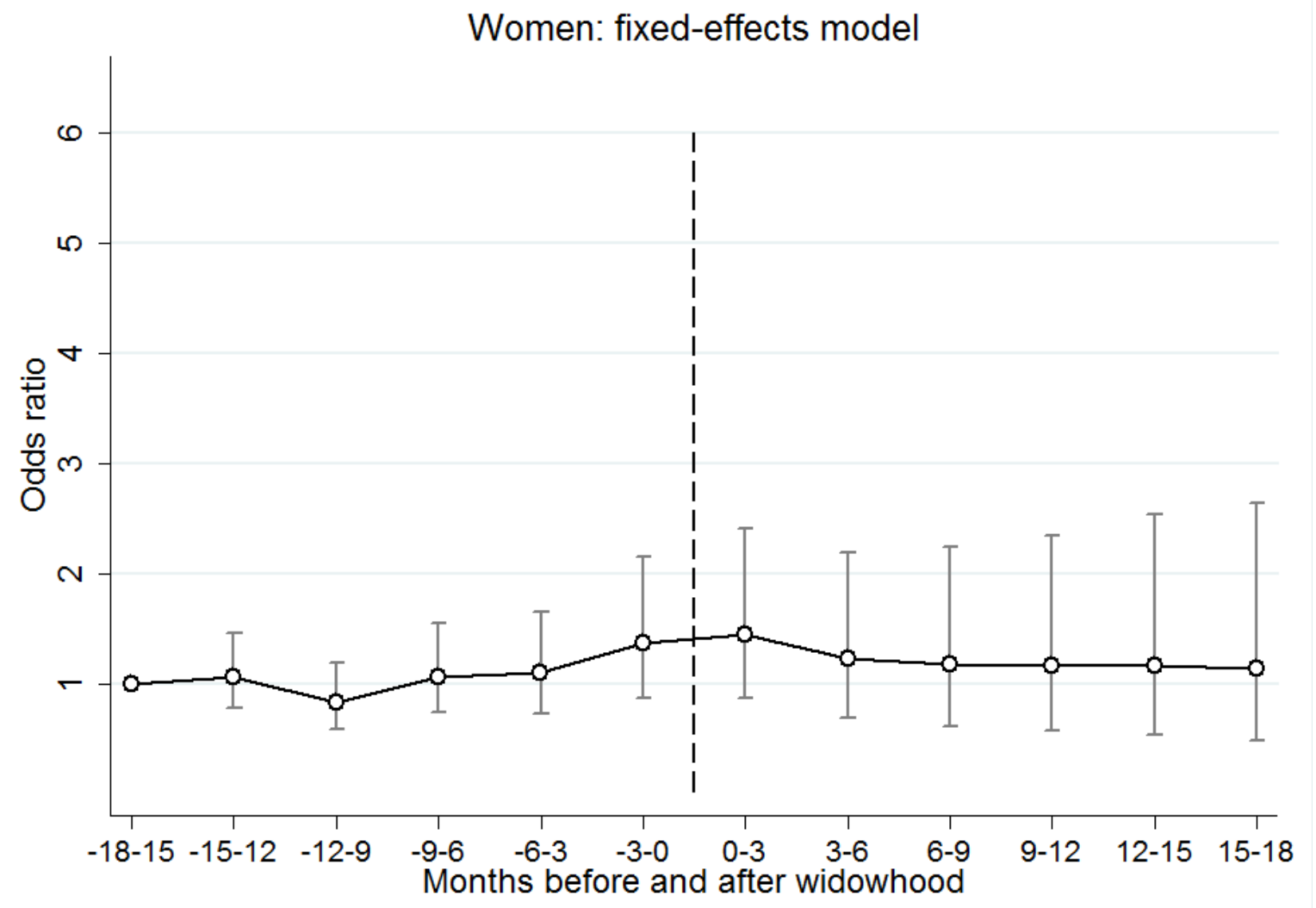

Note: (a) The fixed-effects logistic model controlled for observed time-varying age and calendar year and all unobserved time-invariant confounders. 


\section{REFERENCES}

1 Young M, Benjamin B, Wallis C. The Mortality of Widowers. Lancet 1963;13:454-456.

2 Parkes CM, Benjamin B, Fitzgerald RG. Broken heart: a statistical study of increased mortality among widowers. Br Med J 1969;1:740-743.

3 Mellstrom D, Nilsson A, Oden A, et al. Mortality among the widowed in Sweden. Scand J Soc Med 1982;10:33-41.

4 Jagger C, Sutton CJ. Death after marital bereavement--is the risk increased? Stat Med 1991;10:395-404.

5 Schaefer C, Quesenberry CP,Jr, Wi S. Mortality following conjugal bereavement and the effects of a shared environment. Am J Epidemiol 1995;141:1142-1152.

6 Martikainen P, Valkonen T. Mortality after death of spouse in relation to duration of bereavement in Finland. J Epidemiol Community Health 1996;50:264-268.

7 Manor O, Eisenbach Z. Mortality after spousal loss: are there socio-demographic differences? Soc Sci Med 2003;56:405-413.

8 Elwert F, Christakis NA. Widowhood and race. Am Sociol Rev 2006;71:16-41.

9 Kaprio J, Koskenvuo M, Rita H. Mortality after bereavement: a prospective study of 95,647 widowed persons. Am J Public Health 1987;77:283-287.

10 Martikainen P, Valkonen T. Mortality after the death of a spouse: rates and causes of death in a large Finnish cohort. Am J Public Health 1996;86:1087-1093.

11 Elwert F, Christakis NA. The effect of widowhood on mortality by the causes of death of both spouses. Am J Public Health 2008;98:2092-2098.

12 Jones DR. Cancer mortality following widow(er)hood: some further results from the office of population censuses and surveys longtudinal study. Stress medicine 1986;2:129-140. 13 Moon JR, Glymour MM, Vable AM, et al. Short- and long-term associations between widowhood and mortality in the United States: Iongitudinal analyses. J Public Health (Oxf) 2014;36:382-389.

14 Stroebe M, Schut H, Stroebe W. Health outcomes of bereavement. Lancet 2007;370:1960-1973. 
15 Stroebe W, Stroebe MS. Bereavement and Health: The Psychological and Physical Consequences of Partner Loss. Cambridge: Cambridge University Press 1987.

16 Mostofsky E, Maclure M, Sherwood JB, et al. Risk of acute myocardial infarction after the death of a significant person in one's life: the Determinants of Myocardial Infarction Onset Study. Circulation 2012;125:491-496.

17 Vitlic A, Khanfer R, Lord JM, et al. Bereavement reduces neutrophil oxidative burst only in older adults: role of the HPA axis and immunesenescence. Immun Ageing 2014;11:13-4933-11-13. eCollection 2014.

18 Khanfer R, Lord JM, Phillips AC. Neutrophil function and cortisol:DHEAS ratio in bereaved older adults. Brain Behav Immun 2011;25:1182-1186.

19 Vable AM, Subramanian SV, Rist PM, et al. Does the "widowhood effect" precede spousal bereavement? Results from a nationally representative sample of older adults. Am J Geriatr Psychiatry 2015;23:283-292.

20 Williams BR, Sawyer P, Roseman JM, et al. Marital status and health: exploring pre-widowhood. J Palliat Med 2008;11:848-856.

21 Monserud MA, Markides KS. Changes in depressive symptoms during widowhood among older Mexican Americans: the role of financial strain, social support, and church attendance. Aging Ment Health 2016:1-9.

22 Lichtenstein P, Gatz M, Pedersen NL, et al. A co-twin--control study of response to widowhood. J Gerontol B Psychol Sci Soc Sci 1996;51:P279-89.

23 O'connor CM, Gurbel PA, Serebruany VL. Depression and ischemic heart disease. Am Heart J 2000;140:63-69.

24 Jiang W. Impacts of depression and emotional distress on cardiac disease. Cleve Clin J Med 2008;75 Suppl 2:S20-5.

25 STAKES. Tautiluokitus ICD-10. Systemaattinen osa (Finnish version of the International Statistical Classification of Diseases and Related Health Problems, tenth revision. Volume 1.). 2nd ed. Helsinki: STAKES (National Research and Development Centre for Welfare and Health) 1999. 
26 Allison PD. Fixed effects regression models. Series: Quantitative applications in the social sciences: nro 160. Thousand Oaks, California: Sage Publications 2009.

27 Gunasekara FI, Richardson K, Carter K, et al. Fixed effects analysis of repeated measures data. Int J Epidemiol 2014;43:264-269.

28 Rolden HJ, van Bodegom D, Westendorp RG. Changes in health care expenditure after the loss of a spouse: data on 6,487 older widows and widowers in the Netherlands. PLoS One 2014;9:e115478.

29 Laugsand LE, Vatten LJ, Platou C, et al. Insomnia and the risk of acute myocardial infarction: a population study. Circulation 2011;124:2073-2081.

30 Huxley RR, Woodward M. Cigarette smoking as a risk factor for coronary heart disease in women compared with men: a systematic review and meta-analysis of prospective cohort studies. Lancet 2011;378:1297-1305.

31 Poikolainen K. It can be bad for the heart, too - drinking patterns and coronary heart disease. Addiction 1998;93:1757-1759.

32 Mancia G. Blood pressure reduction and cardiovascular outcomes: past, present, and future. Am J Cardiol 2007;100:3J-9J.

33 Lee S, Colditz GA, Berkman LF, et al. Caregiving and risk of coronary heart disease in U.S. women: a prospective study. Am J Prev Med 2003;24:113-119.

34 Buyck JF, Ankri J, Dugravot A, et al. Informal caregiving and the risk for coronary heart disease: the Whitehall II study. J Gerontol A Biol Sci Med Sci 2013;68:1316-1323.

35 Christakis NA, Allison PD. Mortality after the hospitalization of a spouse. N Engl J Med 2006;354:719-730.

36 Fosbol EL, Peterson ED, Weeke P, et al. Spousal depression, anxiety, and suicide after myocardial infarction. Eur Heart J 2013;34:649-656. 